\title{
Teaching in IP Schools: An Analysis of Teachers' Experiences as Input to Pre-Service Teacher Education
}

\author{
Riza S. Reyteran \\ Occidental Mindoro State College, San Jose, Occidental Mindoro, Philippines \\ rizareyteran@gmail.com
}

DOI: http://doi.org/ 10.36892/ijlls.v3i4.758

$\begin{array}{ll}\begin{array}{l}\text { Received: } \\ \text { 13/11/2021 }\end{array} & \text { Thstract } \\ \text { Accepted: } & \text { teachers of indigenous students are fully equipped to handle multicultural } \\ 30 / 11 / 2021 & \text { classes. Hence, with an end goal of identifying inputs that could enhance pre- } \\ & \text { service teacher education, this study was conducted to determine the profile, } \\ & \text { experiences, knowledge, attitudes, and skills of the randomly selected } \\ \text { Keywords: } & \text { teachers of indigenous students in the province of Occidental Mindoro. The } \\ \text { teacher } & \text { data were gathered online through a questionnaire that underwent validity } \\ \text { education, } & \text { and reliability tests. Findings reveal that the teachers are graduates of } \\ \text { Teacher's } & \text { bachelor of Elementary Education and have been teaching in the IP schools } \\ \text { experiences, } & \text { for not more than three years. The teachers frequently experience } \\ \text { Teaching IP } & \text { implementing the curriculum, monitoring student's progres, and living with } \\ \text { students } & \text { the IP community, and occasionally experience travelling to and from the IP } \\ & \text { community as they embark on the day-to-day activities of teaching their IP } \\ & \text { students. The knowledge, attitudes, and skills they have acquired from their } \\ \text { pre-service teacher education curriculum have prepared them in teaching IP }\end{array}$

\section{INTRODUCTION}

The second pillar of the Philippine Development Plan for 2017 - 2022, which focused on inequality-reducing transformation, aims to accelerate human capital development. To attain this, one of the strategies identified by the government is to achieve accessible, relevant and liberating basic education for all by continuing curricular reforms and enhancing teacher competencies.

Relatively, in its earlier quest to reduce social inequality, the Department of Education initiated curricular reforms through its National Indigenous Peoples Education Policy Framework (2011) and K-12 program (2013; 2019). These reforms required the Commission of Higher Education to review its existing guidelines and create new policies and standards for the offering of the teacher education programs in the country (2017). 
Despite the development, curriculum reviews in state colleges and universities in the Philippines consider the participation of graduates who have experienced teaching in marginalized and indigenous communities. Curriculum reviews merely focused on following the CHED Memorandum Orders governing the operations of teacher education programs (2017), designing and revising syllabus (Zeegers, 2012), and involving the participation of the stakeholders such as students, parents, teachers, school principals, local government units, and alumni who were available during the conduct of the review. These reviews mainly identify subjects to be offered, attributes to be developed, enhancement programs for licensure examination and employment that will be provided to graduating students (Janer et al., 2015). Consequently, curriculum in teacher education institutions focused on developing the teaching competencies and acquiring the content of their specialization. Hence, as future teachers, trainees-students in the program are trained to teach with an end goal of attaining the objectives set for the subjects and mainly use culture, not always of the marginalized and indigenous peoples, as content or theme of the lesson. With the end goal of helping the students pass examinations, teachers concentrate on transferring the knowledge, skills and attitudes outlined in their lesson plans (Hoa \& Vien, 2019). The students do not learn how to teach indigenous students in indigenous communities (Hudson \& Alquist, 2003). It is in this context that this study was conceptualized.

\section{LITERATURE REVIEW}

\subsection{Indigenous Peoples Education}

The United Nations Declaration (2007) on the Rights of Indigenous Peoples (IPs) identified three significant rights relative to the education of indigenous peoples, namely to establish and control their educational systems and institutions, right to all levels and forms of education without discrimination, and to have access to an education in their own culture and language, whenever possible. This declaration reiterated and strengthened the rights of indigenous peoples in the Philippines stated in RA 8371 such as freedom from discrimination, right to equal opportunity and treatment, and the educational system.

To support the IPs, the National Commission on Indigenous Peoples, in collaboration with the Department of Education and Commission on Higher Education outlined the scope of the right to education of the indigenous peoples. These include the curricula and appropriate teaching materials and resources; the equitable distribution, selection and implementation of scholarship programs; appropriate career development; training of teachers for IP communities; construction of school buildings in IP communities; inclusion of IPs resistance to colonization in the academic curricula, in the context of IPs assertion and defense of their freedom, independence and territorial integrity and culture; and, establish schools for living traditions and cultural heritage (NCIP AO 1 s 1998, Sec. 8). However, notwithstanding the efforts of the government to educate indigenous peoples, underachievement is common among indigenous peoples due to low educational motivation and its consequences. IP students faced numerous challenges in gaining and/or maintaining adequate motivation for education. They did not enjoy sufficient conducive conditions for formal schooling, and their living environment was not appropriate for good educational performance (Tran, 2013). Complementary to this is the teachers' lack of training to teach IP students (Hudson \&Alquist, 2003).

Hence, recognizing the vulnerability of the marginalized indigenous peoples in the Philippines who have poor access to culture-responsive basic education, the Department of Education issued the DepEd Order No. 62, series of 2011. With the admission that schools accessible to IPs have limited or no capacity to provide culturally appropriate education, the 
department issued the policy framework on indigenous peoples' education. This policy aims to maintain an education system that will recognize, protect, and promote the rights and welfare of indigenous cultural communities (ICCs)/ Indigenous Peoples (IPs), as well as equip them with the knowledge and skills needed to face various social realities. Adopting this framework, trainings and seminars were provided to the teachers who will be teaching IP students, making them responsive to their learning needs. Nevertheless, these are short-term trainings where the main purpose was to introduce to the teachers the culture of the indigenous peoples and identify strategies on how to teach culture-responsive lessons, in general, to the IP learners. These trainings and seminars given on semestral breaks are not enough to teach the teachers on how to teach among IP students (Ocampo \& Delgado, 2014).

\subsection{Pre-service Teacher Education}

Similarly, the Commission on Higher Education (CHED) has revised its curriculum for pre-service teacher education to incorporate inclusive education and to address other changes brought about by the K-12 curriculum of the Department of Education (CMO Nos. $74 \&$ 75, s. 2017). However, it did not explicitly define the competencies necessary to be developed for the teachers of indigenous peoples. Although the policies, standards and guidelines for the offering of teacher education programs expect the student-teacher to facilitate learning using a wide range of teaching methodologies and delivery modes appropriate to specific learners and their environments; and develop innovative curricula, instructional plans, teaching approaches, and resources for diverse learners, only two courses were allocated for these purposes: the "Teacher and the Community, School Culture and organizational Leadership and the Foundation of Special and Inclusive Education" which focus on the introduction of philosophies, theories and legal bases only. These subjects are even offered in the third year of the curriculum after all strategies on how to teach to grade school students are already taken by the student teachers for primary education.

Consequently, the teachers did not possess the knowledge, skills, and attitudes on how to teach their IP students (Lu, 2013). Teachers reported that they do not know how to handle them. In mainstream classes, they are treated like the mainstream students; they are given similar lessons and activities (Chang, 2011). Hence, their needs as indigenous students are not properly addressed. Understandably, with limited ideas on how to teach IP students, teachers can only maximize what they know.

Pre-service teacher education plays an important role on how the pre-service teachers will educate their IP students in the future. With the changing landscape of classes, teacher education students must be prepared on how to handle multicultural classrooms (Mangila, 2018). They must be prepared to cater for the needs of different students, including the indigenous people. The strategies and curriculum content that will be provided to them must prepare them to foster cross-cultural understanding and awareness of multiple cultures in the classroom to include the migrants or students who transferred from other provinces, indigenous whose culture is different from the mainstream and foreign students. However, this does not happen in real life. Their courses had not prepared the teacher training to with these differences. They lack practical applications of the theories they learned. They are not deployed to schools with multicultural set up for their internship (Premier \& Miller, 2010a). The supervisory support provided during the internship of the student- teachers are limited and not enough for them to learn strategies and practices in teaching students (Al-Jaro, Asmawi \&Abdul-Ghafour, 2020).

Analysis of the pre-service education in the Philippines revealed that the objectives are focused on allowing the pre-service teachers to acquire insights from the practicum experience and to apply all the theories, principles, strategies, and techniques learned from their previously 
taken general education, specialization, and professional education courses. Their learning activities or experiences include: a) conducting regular classroom observations; b) lesson planning; c) using varied teaching approaches, methods and strategies; d) preparing instructional materials; e) actual demonstration teaching; f) using different questioning techniques; g) managing the classroom; h) conducting post-conferences; i) assessing learning outcomes; j) structuring the classroom bulletin boards; k) participating in school-related activities; 1) conducting parent conferences; m) performing auxiliary services; and $n$ ) conducting other classroom- and school-based activities. The assessment of the performance of practice teachers considers the assessment of the cooperating teachers on daily teaching, the practicum portfolio submitted, and the final demonstration teaching, that often gets the highest weight in their final grades. The assessment procedures reveal a variety of sources, with emphasis on actual demonstration teaching and the use of portfolio of artefacts that could explain the competencies that the practice teachers could demonstrate (Calapardo, Balagtas \& Dacanay, 2016).

The curriculum failed to consider that after graduation these teacher education students may be hired by the Department of Education and deployed to remote and rural areas where students or majority of them are indigenous. In a study conducted by Hudson and Ahlquist (2003), the student- teachers revealed that their courses in preparation for becoming a teacher are not enough for them to learn the skills of teaching, especially to the indigenous learners. They said that they wanted to study more courses that aim at learning the strategies, methods, and classroom management to better prepare them as teachers in the future (Ulla, 2016). However, if a certain subject will be allotted for the teaching of cultural awareness and sensitivity; information about the needs of indigenous students; and techniques or strategies on how to teach IP students (Premier \& Miller, 2010a), these teacher education students will be able to guide the indigenous students towards improved performance and achievement, and self-determination.

\subsection{Theoretical Framework}

This study is anchored on the theory of Culturally Responsive Teaching of Gay (2002). This theory posits that effective teaching to indigenous students requires consideration of their cultural characteristics, experiences, and perspectives. It believes that learning become meaningful, appealing, and successful on the parts of the indigenous students when academic knowledge is situated within their lived experiences and frame of references. Considering these, the teachers must have explicit knowledge of the culture of the indigenous students they are going to teach. Their curriculum must be able to make them culturally responsive teachers. These can be possible when experiences of those have been teaching in indigenous communities are considered in the revision of teacher education curriculum.

\subsection{Research Questions}

This study aims at determining the experiences of the teachers in teaching IP students as input to teacher education curriculum. Specifically, it intended to:

1. determine the profile of the respondents in terms of educational qualification and numbers of years teaching in IP schools;

2. explore the experiences of the teachers of IP students in terms of the following: a) implementing the curriculum, b) monitoring student's progress, c) living with IP community, and d) travelling to and from the IP community;

3. determine the teachers' level of agreement on the knowledge, attitudes and skills learned by the respondents from their pre-service education; 
4. determine which among the knowledge, attitudes and skills learned by the respondents from their pre-service education have prepared them in teaching IP students; and

5. identify possible inputs for the enhancement of the curriculum in pre-service teacher education.

\subsection{Significance of the Study}

This study will provide the Teacher Education Institutions (TEIs) the knowledge, skills and attitudes that they might consider in reviewing teacher education curriculum to better prepare the future teachers of Indigenous Peoples.

The results of this study will also provide information that the future teachers may consider understanding, learning and acquiring to prepare them for the life in rural areas with IP schools or in schools with IP students.

\section{METHODOLOGY}

This descriptive study was conducted among teachers of IP schools in Southern Luzon in the Philippines. The respondents who were randomly selected were asked to answer a questionnaire which focuses on their experiences as teachers in IP schools, the relevance of their pre-service education in teaching IP students and their suggestions that could enhance the pre-service teacher education curriculum. The instrument was validated by the experts in the field of education. With a Cronbach's Alpha value of .930, it was found reliable. The instrument was made available online thru the Google form and the link was provided to the respondents.

In analyzing the data of this study, the researcher utilized descriptive statistics, and thematic analysis designed by Braun \& Clarke (2006). For the profile of the respondents, frequency distribution and percentage were used. On the other hand, to determine the experiences and the relevance of their pre-service education in teaching indigenous students, weighted mean was computed. A thematic analysis was conducted on the possible inputs they have identified for the enhancement of teacher education curriculum. According to Braun and Clarke (2006), thematic analysis is the process of identifying patterns or themes within qualitative data. The themes can be classified in two: semantic and latent. Semantic theme is 'within the explicit or surface meanings of the data and the analyst is not looking for anything beyond what a participant has said or what has been written.' In contrast the latent theme looks beyond what has been said and 'starts to identify or examine the underlying ideas, assumptions, and conceptualizations - and ideologies - that are theorized as shaping or informing the semantic content of the data.

\section{RESULTS AND DISCUSSIONS}

This section presents the analysis and interpretation of the results and findings from the data gathered to answer the research objectives.

\section{Profile of the respondents}

Based on table 1, the data on the distribution of the respondents reveal that 29 or $76.3 \%$ of the teachers of IP students are graduates of Bachelor of Elementary Education while 1 or $2.6 \%$ is a graduate of Bachelor of Elementary and Secondary Education, Bachelor of Technical teacher Education, Bachelor of Science in Religious Education and Bachelor of Science in Commerce.

Meanwhile. 22 or $57.9 \%$ of the teachers have been teaching in the IP schools for not more than three (3) years and only 2 or $5.3 \%$ have been in the IP schools for 10 to 13 years. 
These findings reveal that majority of the teachers of IP students have earned an education degree that is relevant to their profession. However, it also reveals that majority of them are neophyte in the profession. This imply that although the teachers were trained on how to teach IP students (Calapardo, Balagtas \& Dacanay, 2016), they are new in the profession and have limited exposure to multicultural classrooms (Premier \& Miller, 2010b).

Table 1. Profile of the respondents

\begin{tabular}{|c|c|c|}
\hline 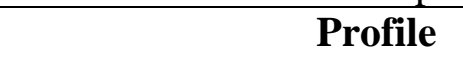 & Frequency & Percentage \\
\hline \multicolumn{3}{|l|}{ Educational Qualification } \\
\hline BEED & 29 & 76.3 \\
\hline BSED & 3 & 7.9 \\
\hline BESED & 1 & 2.6 \\
\hline BSAED & 2 & 5.3 \\
\hline BTTE & 1 & 2.6 \\
\hline BS in Religious Education & 1 & 2.6 \\
\hline $\mathrm{BS}$ in Commerce & 1 & 2.6 \\
\hline Total & 38 & 100.0 \\
\hline \multicolumn{3}{|c|}{ Number of Years Teaching in IP School } \\
\hline $.5-3$ & 22 & 57.9 \\
\hline $4-6$ & 11 & 28.9 \\
\hline $7-9$ & 3 & 7.9 \\
\hline $10-13$ & 2 & 5.3 \\
\hline Total & 38 & 100.0 \\
\hline
\end{tabular}

\section{Experiences of the teachers of IP students}

The experiences of the teachers in teaching IP students are presented in Table 2. With a grand mean of 3.61, the table reveals that the teachers frequently experience implementing the curriculum $(\mathrm{m}=3.82)$, monitoring student's progress $(\mathrm{m}=4.19)$, living with the IP community $(\mathrm{m}-3.78)$ and occasionally experience travelling to and from the IP community $(\mathrm{m}=2.64)$ as they embark on the day-to-day activities of teaching their IP students.

The item with the highest mean is "The people in the IP community treats me with respect." with a mean value of 4.66 and interpreted as "Very frequently". This is followed by "I am able to monitor my students' individual progress in my class." With a mean value of 4.55 also interpreted as "Very frequently". On the other hand, the item with lowest mean is "I find it easy to travel from my hometown to the IP community where the school is located." with a mean value of 2.45 and interpreted as "Rarely".

This reveals that the teachers found no difficulty in living with the IP communities; however, the means of travelling to and from these communities are not regularly done. This implies difficulty in accessing mode of transportation or far distance of the communities to the town proper. It adds additional burden of accessing and transporting resources from the main town to the IP communities, a training that was not given emphasize pre-service (Calapardo, Balagtas \& Dacanay, 2016).

Table 2. Experiences of the teachers of IP students.

\begin{tabular}{lc}
\hline Implementing the curriculum & Mean Interpretation \\
\hline
\end{tabular}


1. I am able to implement my lesson as planned.

$3.82 \quad$ Frequently

2. I am able to use the resources in the community in teaching

4.11 Frequently lessons to my students.

3. I am able to follow the curriculum assigned for a particular $3.87 \quad$ Frequently level of my students.

4. I am able to finish the whole plan for my students in a school $3.53 \quad$ Frequently year.

5. I am able to accomplish the objectives set every grading

3.79 Frequently period.

Overall Mean $\quad 3.82 \quad$ Frequently

\section{Monitoring student's progress}

1. I am able to monitor my students' individual progress in my class.

$4.55 \quad$ Very

I am able to provide feedback to my students on their frequently performance in class.

3. I am able to communicate with the parents of my students regarding the performance of their children.

4. I am able to conduct remedial classes for students who have difficulty in class.

5. The IP students are able to pass the daily exercises and the periodical exams.

Overall Mean

\section{Travelling to and from the IP community}

1. I find it easy to travel from my hometown to the IP community where the school is located.

2. I travel to and from the IP community every day.

4.39 Frequently

4.29 Frequently

4.16 Frequently

$3.55 \quad$ Frequently

3. There are various means of transportation to and from the IP community

4. The IP community where the school is located is accessible.

5. Traveling to and from the IP community is safe. Overall Mean

$4.19 \quad$ Frequently

$2.45 \quad$ Rarely

2.74 Occasionally

2.50 Occasionally

2.74 Occasionally

2.76 Occasionally

2.64 Occasionally

\section{Living with IP community}

1. I live in the IP community where the school is located.

3.26 Occasionally

2. The IP community has a peaceful living environment.

Occasionally

3. The IP community has enough supply of food and water for

Occasionally the people.

4. I feel safe living in the IP community.

$3.84 \quad$ Frequently

5. The people in the IP community treats me with respect.

Legend: 1.00-1.49 - Never; 1.50-2.49 - Rarely; 2.50-3.49 - Occasionally; 3.50-4.49 Frequently; 4.50-5.00 - Very frequently

Knowledge, attitudes, and skills learned by the respondents from their pre-service teacher education 
The knowledge, attitudes, and skills acquired by the teachers from their pre-service teacher education are presented in Table 3 . With an overall mean of 4.37, the teachers "agreed" that they have learned from their pre-service teacher education the knowledge, attitudes, and skills necessary to perform their duties as teachers. The item with the highest mean is "Using varied teaching approaches, methods and strategies" with a mean value of 4.50 and interpreted as "Strongly agree". This is followed by "Lesson Planning" with a mean value of 4.45 and interpreted as "Agree".

However, the item with the lowest mean is "Performing auxiliary services" with a mean value of 4.00 and interpreted as "Agree". This is followed by "Using indigenous materials in designing instructional materials" with a mean value of 4.08 also interpreted as "Agree".

These findings reveal that although the teachers are equipped with the skills on how to teach, they have concerns in performing services other than this. Likewise, it seems that the teachers have also issues in designing instructional materials out of indigenous materials. It supports the findings of Chang (2011) which states that the needs of the indigenous students are not properly addressed in the design of lessons and activities.

Table 3. Knowledge, attitudes, and skills learned by the respondents from their pre-service teacher education

\begin{tabular}{lcc}
\hline \multicolumn{1}{c}{ Knowledge, Attitudes and Skills } & Mean & Interpretation \\
\hline 1. Lesson planning & 4.45 & Agree \\
2. Using varied teaching approaches, methods and strategies & 4.50 & Strongly agree \\
3. Preparing instructional materials for diverse learners & 4.26 & Agree \\
4. Using indigenous materials in designing instructional & 4.08 & Agree \\
materials & & \\
5. Actual teaching & 4.42 & Agree \\
6. Managing the classroom & 4.26 & Agree \\
7. Assessing learning outcomes & 4.29 & Agree \\
8. Using different questioning techniques & 4.32 & Agree \\
9. Designing different evaluation and assessment tools & 4.11 & Agree \\
10. Providing performance feedback to students & 4.24 & Agree \\
11. Identifying individual differences of students & 4.24 & Agree \\
12. Mastery of pedagogical content knowledge & 4.18 & Agree \\
13. Understanding cultural awareness and sensitivity & 4.24 & Agree \\
14. Understanding the needs of indigenous students & 4.32 & Agree \\
15. Identifying teaching techniques or strategies for IP & 4.16 & Agree \\
students & & \\
16. Structuring the classroom bulletin boards & 4.13 & Agree \\
17. Participating in school-related activities & 4.21 & Agree \\
18. Conducting parent conferences & 4.29 & Agree \\
19. Performing auxiliary services & 4.00 & Agree \\
20. Participating in community-based activities & 4.24 & Agree \\
\end{tabular}

Legend: 1.00-1.49 - Strongly disagree; 1.50-2.49 - Disagree; 2.50-3.49 - Neither agree nor disagree; 3.50-4.49-Agree; 4.50-5.00 - Strongly agree 
Table 4 presents the knowledge, attitudes, and skills learned by the teachers from their pre-service education which have prepared them in teaching their IP students. With an overall mean of 4.37, the teachers "Agree" that the knowledge, attitudes, and skills they have learned from their pre-service teacher education have prepared them in teaching their IP students.

The items with the highest mean are "Actual teaching", "Understanding cultural awareness and sensitivity", and "Understanding the needs of indigenous students" with a mean value of 4.47 and interpreted as "Agree".

However, the item with the lowest mean is "Performing auxiliary services" with a mean value of 4.16 also interpreted as "Agree".

These findings reveal that understanding the culture of the IP students is significant in the teaching and learning process. Hence, if the future teachers will be given education on cultural awareness and sensitivity; information about the needs of indigenous students; and techniques or strategies on how to teach IP students (Premier \& Miller, 2010a), they will be able to guide the indigenous students towards improved performance and achievement, and self-determination.

Table 4. Knowledge, attitudes, and skills learned by the respondents from their pre-service education have prepared them in teaching IP students.

\begin{tabular}{lcc}
\multicolumn{1}{c}{ Knowledge, Attitudes and Skills } & Mean & Interpretation \\
\hline 1. Lesson planning & 4.37 & Agree \\
2. Using varied teaching approaches, methods, and & 4.42 & Agree \\
strategies & & \\
3. Preparing instructional materials for diverse learners & 4.45 & Agree \\
4. Using indigenous materials in designing instructional & 4.39 & Agree \\
materials & & \\
5. Actual teaching & 4.47 & Agree \\
6. Managing the classroom & 4.42 & Agree \\
7. Assessing learning outcomes & 4.39 & Agree \\
8. Using different questioning techniques & 4.37 & Agree \\
9. Designing different evaluation and assessment tools & 4.29 & Agree \\
10. Providing performance feedback to students & 4.39 & Agree \\
11. Identifying individual differences of students & 4.42 & Agree \\
12. Mastery of pedagogical content knowledge & 4.45 & Agree \\
13. Understanding cultural awareness and sensitivity & 4.47 & Agree \\
14. Understanding the needs of indigenous students & 4.47 & Agree \\
15. Identifying teaching techniques or strategies for IP & 4.37 & Agree \\
students & & \\
16. Structuring the classroom bulletin boards & 4.18 & Agree \\
17. Participating in school-related activities & 4.26 & Agree \\
18. Conducting parent conferences & 4.39 & Agree \\
19. Performing auxiliary services & 4.16 & Agree \\
20. Participating in community-based activities & 4.24 & Agree \\
& Agree \\
\hline
\end{tabular}


Legend: 1.00-1.49 - Strongly disagree; 1.50-2.49 - Disagree; 2.50-3.49 - Neither agree nor disagree; 3.50-4.49-Agree; 4.50-5.00 - Strongly agree

Possible inputs that could be included in the curriculum of pre-service education to better prepare the future teachers of IP students

The teachers provided several recommendations that could enhance the pre-service teacher education curriculum. Using a thematic analysis, five themes emanate from their answers as follows:

a. Inclusion of IP education in the Teacher Education curriculum

The teachers suggested that in order to prepare the future teachers of Indigenous Peoples, IP education may be included in the curriculum. This includes contextualization of the curriculum, teaching the future teachers the techniques and strategies that will consider the culture of the IP students, designing instructional materials using available indigenous resources and even preparing curriculum guide for IP students.

b. Awareness program on the culture of Indigenous People

The teachers also suggested the inclusion of program that will increase the awareness of the future teachers on the culture of Indigenous Peoples. This includes familiarization with their culture, language and lifestyle and being culture sensitive. It is also better if the future teachers are aware of the location of these communities in the province so that they will be prepared on the kind of life they have to deal with once they are employed to teach in these communities.

c. Inclusion of IP language in the Teacher Education curriculum

The teachers also suggested possible inclusion of IP language in the teacher education curriculum. This, according to them, will facilitate understanding between the teachers and the students and the community. Learning or understanding the language of the IP students could also enhance the learning process as it supports the mother-tongue based education.

d. Training on how to handle combined or multigrade class

Another suggestion from the teachers is the inclusion of training on how to handle combined or multigrade class. This includes lesson planning, teaching techniques and strategies, and classroom management.

e. $\quad$ Conducting immersion activities in IP or minority schools

Lastly, the teachers believed that the best way to comprehend teaching in IP students is to immerse the future teachers in these schools. This could be made possible through field visitation, field study or even practice teaching.

\section{CONCLUSIONS}

Considering the findings of this study, the following conclusions were drawn:

1. Majority of the respondents are graduates of Bachelor of Elementary Education and are newly hired in the profession. 
2. The teachers frequently experience implementing the curriculum, monitoring student's progress, and living with the IP community, and occasionally experience travelling to and from the IP community as they embark on the day-to-day activities of teaching their IP students.

3. The teachers agree that they have acquired the necessary knowledge, attitudes and skills from their pre-service teacher education curriculum.

4. The teachers agree that these knowledge, attitudes and skills have prepared them in teaching IP students.

5. The following themes emanate from the teachers' suggestions on how to enhance the pre-service teacher education curriculum: inclusion of IP education, awareness program on the culture of Indigenous People, inclusion of IP language, training on how to handle combined or multigrade class, and conducting immersion activities in IP or minority schools.

\subsection{Implications for Educational Practice and for Future Research}

In the light of the deployment of the Department of Education in IP schools of newly hired teachers who are mostly fresh graduates, training them on how to be prepared is crucial to their success as teachers of IP students.

Moreover, teacher education institutions may consider the suggestions of the teachers who have first-hand experiences in teaching IP students in reviewing and revising the existing curriculum of pre-service teacher education.

Lastly, this study may be replicated to include a bigger number of respondents or consider other indigenous communities.

\section{REFERENCES}

Al-Jaro, M.S., Asmawi, A. \& Abdul-Ghafour, A.Q.K. (2020). Supervisory support received by EFL student teachers during practicum: The missing link. International Journal of Language and Literary Studies, 2 (4), 22-41.

Calapardo, R. A. B., Balagtas, M.V. \& Dacanay, A.G. (2016). Analysis of student teaching program of selected teacher education institutions and its alignment with the Professional Standards for Teachers. The Normal Lights, 10 (1), 109-129.

Chang, M. (2011). Academic performance of language minority Students and all-day kindergarten: A longitudinal study. School Effectiveness and School Improvement, 23(1), 1-28.

CHED (2017). Memorandum Order 74 s 2017, "Policies, Standards and Guidelines for Bachelor of Elementary Education (BEEd)." Available at: < $\underline{\text { https://ched.gov.ph/wp- }}$ content/uploads/2017/11/CMO-No.-74-s.-2017.pdf>. Retrieved: January 18, 2020.

CHED (2017). Memorandum Order 75 s 2017, "Policies, Standards and Guidelines for Bachelor of Secondary Education (BSEd)." Available at: <https://ched.gov.ph/wpcontent/uploads/2017/11/CMO-No.-75-s.-2017.pdf >. Retrieved: January 18, 2020.

DepEd (2011). Department Order 62 s 2011, "Adoption of the National Indigenous Peoples Education Policy Framework." Available at: < https://www.deped.gov.ph/wpcontent/uploads/2011/08/DO-No.-62-s.-2011.pdf>. Retrieved: January 18, 2020.

DepEd (2013). Department Order 43 s 2013, "Implementing rules and Regulations (IRR) of Republic Act No. 10533 otherwise known as the Enhanced Basic Education Act of 2013." Available at $:<$ https://www.deped.gov.ph/wpcontent/uploads/2013/09/DO_s2013 43.pdf>. Retrieved: April 13, 2020.

DepEd (2019). Department Order 21 s 2019, "Policy Guidelines on the K to 12 Basic Education

Program." Available at : < https://www.deped.gov.ph/wpcontent/uploads/2019/08/DO_s2019_021.pdf>. Retrieved: April 13, 2020.

Gay, G. (2002). Preparing for culturally responsive teaching, Journal of Teacher Education, $53,106-117$. 
Hoa, C. and Vien, T. (2019). The integration of intercultural education into teaching English: What Vietnamese teachers do and say. International Journal of Instruction, 12 (1), 441456.

Hudson, A. and Ahlquist, R. (2003). Contesting the curriculum in the schooling of indigenous children in Australia and the USA: From Eurocentrism to culturally powerful pedagogies. Comparative Education Review, 47, (1), 64-89.

Janer, S. S., Deri, R.A., Dio, R.V., Marbella, F.D. \& Ricafort, J.D. (2015). Factors on enhancing competitive edge and attributes of graduates as inputs to the development of Teacher Education Enhancement Program (TEEP). Asia Pacific Journal of Multidisciplinary Research, 3 (4), 25-33.

Lu, J. (2013). English learning in Chinese minority areas: The challenges and new directions. Theory and Practice in Language Studies, 3 (4), 556-563.

Mangila, B. B. (2018). Assessment of pre-service teachers on the practice teaching program: Inputs for program enhancement. Asia Pacific Journal of Education, Arts and Sciences, 5 (3) 50-58.

NCIP (1998). Administrative Order 1 s 1998, "Rules and Regulations Implementing Republic Act No. 8371, Otherwise Known as "The Indigenous Peoples' Rights Act of 1997." National Commission on Indigenous Peoples. Available at: $\langle$ https://www.wipo.int/edocs/lexdocs/laws/en/ph/ph083en.pdf $>$. Retrieved: January $18,2020$.

Ocampo, M. and Delgado, P. (2014). Basic education and cultural Heritage: Prospects and challenges. International Journal of Humanities and Social Science, 4 (9), 201-209.

Premier, J. \& Miller, J. (2010a). Preparing pre-service teachers for multicultural classrooms. Australian Journal of Teacher Education, 35 (2).

Premier, J. \& Miller, J. (2010b). Republic Act No. 8371, An Act to Recognize, Protect and Promote the Rights of Indigenous Cultural Communities/ Indigenous Peoples, Creating a National Commission on Indigenous Peoples, Establishing Implementing Mechanisms Appropriating Funds Therefor and for Other Purposes. Available at: <https://www.officialgazette.gov.ph/1997/10/29/republic-act-no-8371/>. Retrieved: January 18, 2020.

Tran, N. (2013). Factors associated with low educational motivation among ethnic minority students in Vietnam. Ritsumeikan Journal of Asia Pacific Studies Volume 32.

Ulla, M. (2016). Pre-service teacher training programs in the Philippines: The student-teachers practicum teaching experience. EFL Journal, 1 (3), 235-250.

United Nations (2007). United Nations Declaration on the Rights of Indigenous Peoples. Available at: < https://www.un.org/development/desa/indigenouspeoples/wpcontent/uploads/sites/19/2018/11/UNDRIP_E_web.pdf>. Retrieved: January 18, 2020.

Zeegers, Y. (2012). Curriculum development for teacher education in Southern Philippines: A simultaneous process of professional learning and syllabus enhancing. International Journal of Educational Development, 32 (2), 207-213.

\section{$\underline{\underline{A U T H O R} S \mathrm{BIO}}$}

Riza S. Reyteran is a Faculty of the College of Teacher Education and the Director for Institutional Quality Assurance of Occidental Mindoto State College in San Jose, Occidental Mindoro, Philippines. She teaches language, literature and education related subjects. She has presented research papers in various conferences. She received her Master in Education with specialization in Administration and Supervision at Divine Word College of San Jose, Occidental Mindoro and currently finishing her dissertation for the Doctor of Philosophy in English Language Education in Philippine Normal University-Manila. 